\title{
Complementary medicines: When regulation results in revolution
}

\author{
L Fourie, BPharm, MSc; F Oosthuizen, BPharm, MSc, PhD; K du Toit, BPharm, MSc, PhD, LLB \\ Discipline of Pharmaceutical Sciences, Faculty of Health Sciences, University of KwaZulu-Natal, Durban, South Africa
}

Corresponding author: L Fourie (liezl.fourie14@gmail.com)

\begin{abstract}
Medicines have evolved over time and so has the realisation of the importance of quality control and regulatory processes. The regulatory practices include all the steps from the development and manufacture of the active ingredients until the medicines reach the consumer. The Medicines Control Council (MCC) is mandated to regulate medicines in South Africa. Complementary medicines were previously perceived to be unregulated, although the Medicines Act does not distinguish between allopathic and complementary medicine. As the era of unregulated complementary medicine ended, the requirements in terms of dossier content left many role-players at odds. However, the MCC has a mandate to ensure that the registration of a medicine is in the interest of the public and that complementary medicine is manufactured in a facility adhering to good manufacturing practice, according to which efficacy and safety are supported by reliable data with a known shelf-life.
\end{abstract}

S Afr Med J 2017;107(6):483-485. DOI:10.7196/SAMJ.2017.v107i6.12055

Medicines have evolved over time and so has the realisation of the importance of quality control and regulatory processes. Catastrophes such as the thalidomide disaster in the late 1950s highlighted the importance of regulating medicines on the grounds of safety, quality and efficacy, which has since been widely accepted and implemented. [1] The most important objective of medicine regulation is to ensure the safety of consumers. As medicine as such is not safe, the choice between the risk and benefit associated with its use needs to be made on the consumer's behalf by means of regulations. The regulatory practices include all the steps from the development and manufacture of the active ingredients, to packaging and distribution, until the medicines reach the consumer. ${ }^{[2]}$ In South Africa (SA), as in other countries, the public has the right to expect that only safe and effective medicines of good quality are allowed on the market, aligned with section 12 of the Constitution of SA. ${ }^{[3]}$

The establishment of the Medicines Control Council (MCC), mandated to regulate medicines in SA, was provided for by the Medicines and Related Substances Act 101 of 1965 (Medicines Act). ${ }^{[2]}$ The Medicines Act provides in section 14(2)(a) that the MCC may from time to time by resolution approved by the minister of health determine that a medicine or class or category of medicines or part of any class or category of medicines mentioned in the resolution shall be subject to registration in terms of the Medicines Act. Medicines were called up for registration according to this section and if a medicine became subject to registration and was not subsequently registered, its sale was prohibited according to section $14(1) \cdot{ }^{[4]}$

\section{Regulation of complementary medicines}

Complementary medicines were previously perceived to be unregulated, although the Medicines Act does not distinguish between allopathic and complementary medicine. In 2002, the MCC published a notice, 'Call up notice for medicines frequently referred to as complementary medicines in terms of the Medicines and Related Substances Act, 1965 (Act No. 101 of 1965)'.[5] The Notice also indicated that the data compiled from this call-up will enable
Council to audit all products currently available on the market. Council will review the claims of safety, quality and efficacy for all identified products and will determine whether any such claims constitute a public health hazard and act accordingly. The MCC requested manufacturers to submit a document providing limited information on the medicines. The shortened application form included administrative information, a copy of the label and package insert, a breakdown of the unit formulation, and a list of other countries in which the product is sold. These application forms did not contain sufficient information for evaluation of safety, quality and efficacy and were intended as an audit process only. MBR20.8 documents were issued by the MCC as confirmation of receipt of the abbreviated application and did not indicate product registration. ${ }^{[6]}$ Even though the audit period, as indicated in the Notice, expired on 22 August 2002, submissions from manufacturers continued, to some extent to obtain a National Pharmaceutical Product/Pricing Index (NAPPI) code. ${ }^{[7]}$

In the case between the Treatment Action Campaign $v$ Rath and Others (12156/05 (2008) ZAWCHC 34), Rath was found guilty of selling and distributing medicines that were not registered and that contained scheduled substances ${ }^{[8]} \mathrm{He}$ was also found guilty of making false and unauthorised statements about the efficacy of medicines. In the High Court judgment Judge Zonde ruled against Rath and others on the grounds of the main purpose of the 2002 call-up by the MCC. He further mentioned that the MCC has failed to determine the correctness of the claims made for products that have been submitted. Furthermore, the MCC did not carry out an independent assessment of quality of these products; therefore, the products must be considered to be potentially unsafe. Any claims made about these medicines would therefore be considered to be misleading. The regulation of complementary medicines did not entail an amendment to the Act, as sections 14 and 15 imply that they have already been 'called up for registration'. This cannot be repealed by the 2002 call-up.

However, Government Notice R870, published in the Government Gazette 37032 of 15 November 2013, incorporated new General 
Regulations to the Medicines Act, which finally called up complementary medicines. ${ }^{[9]}$ This amendment provides that all complementary medicines will be subject to the same legislative control as allopathic medicines. Complementary medicines will be evaluated for safety, efficacy and quality and claims made will have to be substantiated. Furthermore, manufacturers, distributors, importers and exporters of complementary medicines will have to be licenced.

The amended Regulations defined complementary medicines as any substance or mixture of substance that $(i)$ originates from plants, minerals or animals; (ii) is used or intended to be used for, or manufactured or sold for use in assisting the innate healing power of a human being or animal to mitigate, modify, alleviate or prevent illness or the symptoms thereof or abnormal physical or mental state; and (iii) is used in accordance with the practice of the professions regulated under the Allied Health Professions Act, 1982 (Act No. 63 of 1982). ${ }^{[9]}$

The disciplines or practices mentioned in part (iii) of the definition include homeopathy, western herbal medicine, traditional Chinese medicine, Ayurveda, Unani medicine (Unani-Tibb) and aromatherapy. ${ }^{[10]}$ Each discipline has different requirements governed by its own references and pharmacopoeia subject to the current science and knowledge of the particular discipline.

The definition proved problematic, as it does not provide for the origin, claims and/or uses of all perceived complementary medicines such as certain vitamin products and probiotics, which are not discipline specific and have not been used in accordance with the practice of the professions regulated under the Allied Health Professions Act as indicated in the abovementioned definition. ${ }^{[9,10]}$

An amended definition of complementary medicines has been published for comment, which defines these medicines as any substance or mixture of substances that (i) originates from plants, fungi, algae, seaweeds, lichens, minerals, animals or other substance as determined by Council; and (ii) is used or purports to be suitable for use or is manufactured or sold for use in maintaining, complementing, or assisting the innate healing power or physical or mental state; or to diagnose, treat, mitigate, modify, alleviate or prevent disease or illness or the symptoms or signs thereof or abnormal physical or mental state of a human being or animal; and (iii) is used as a health supplement; or in accordance with those disciplines as determined by Council; or (iv) is declared by the Minister, on recommendation by the Council, by notice in the Government Gazette to be a complementary medicine. ${ }^{[11]}$

The proposed amendments to the complementary medicine definition provide additional origins, widen the claims and added a subcategory, i.e. health supplements, to the initial definition. They also provide for a medicine that does not meet the requirements to be declared a complementary medicine by the Minister on recommendation by the MCC. Combination products, such as products comprised of more than one discipline-specific substance or discipline-specific substance(s) and health supplements, are also classified as a category of complementary medicines.

If a medicine does not meet any of the abovementioned requirements to be defined as a complementary medicine, selling will have to be discontinued and application will have to be made for registration as an allopathic medicine.

The claims of complementary medicines create pharmacological classifications, and medicines have to be submitted on designated dates, depending on their classification, e.g. antiviral complementary medicines had to be submitted by May 2014. The initial submission process will be completed by November 2019. The requirement for only submitting on a designated date in future was that the medicines must have been available for sale in SA on the date of Notice R870. In the meantime, the status quo is maintained and the medicine may be sold unless it contains banned or scheduled substances. ${ }^{[12]}$

Interestingly, the Medicines and Related Substances Amendment Act $2015^{[13]}$ provides for the establishment of the SA Health Products Regulatory Authority, which will replace the current MCC, but this Act will only become operational after the commencement of the Medicines and Related Substances Amendment Act 2008. ${ }^{[14]}$ It will not have an effect on the call-up or definitions of complementary medicines.

\section{Quallity, safety and efficacy of complementary medicines}

The labels of all complementary medicines must comply with the provisions of section 8 of the General Regulations to Medicines and Related Substances Act, 1965. According to these provisions, the labels must be written in English and at least one other official language and must indicate the category, pharmacological classification and discipline of medicine. Furthermore, the words 'This medicine has not been evaluated by the Medicines Control Council. This medicine is not intended to diagnose, treat, cure or prevent any disease' must be added to the label. ${ }^{[15]}$ Any additional information to the regulations has to be authorised by the MCC.

The quality of complementary medicines is measured in terms of factors such as Good Manufacturing Practice (GMP), Good Laboratory Practice and Good Agricultural and Collection Practices specifications, identification of impurities, analytical validations and stability (International Council for Harmonisation of Technical Requirements for Pharmaceuticals for Human Use (ICH) guidelines), ensuring attributes such as identity, strength and purity of a medicine that have to be met consistently. ${ }^{[16,17]}$

When evaluating the efficacy of complementary medicines, established traditional use, preclinical data and evidence from clinical trials in animals and humans are used. Literature, such as acceptable monographs and pharmacopoeial references, also needs to be taken into account to the extent depending on the risk level of the claim made. The data must support efficacy aligned with the proposed indications and claims on the label and package insert.

Safety may be established by detailed reference to the published literature and/or the submission of original study data. If a complementary medicine has been traditionally used without demonstrating harm, a review of the relevant literature should be provided. Reference should also be made to official monographs supporting safety and toxicological studies, if available. Safety is the ability of the medicine not to cause serious side-effects when assessed against its risk-benefit profile.

\section{Conclusion}

The General Regulations of $2013^{[9]}$ ended an era of unregulated commercialisation of complementary medicine. Unfortunately, the requirements in terms of dossier content left many role-players at odds. Without the much needed pharmacological and scientific knowledge, the compilation of dossiers becomes an insurmountable task. Furthermore, the cost of merely applying, especially for those companies currently selling many products, is daunting. ${ }^{[18]}$ Overcoming these hurdles is extremely expensive and time-consuming. Conflict between reputable trademarks and allowed proprietary names and acceptable levels of proof of efficacy, among other issues, may also cause disputes between the industry and the MCC. The majority of complementary medicines that were on the market before the General Regulations came into effect, are now under threat and 
the nature of the industry will change once the new laws are fully implemented.

However, the MCC has a mandate to ensure that the registration of a medicine is in the interest of the public. It will surely not be in the public interest to register a complementary or any other medicine that is manufactured in a facility not adhering to GMP, according to which efficacy and safety are not supported by trustworthy data, and the shelf-life is not known. As stated above, medicine as such is not safe and the choice between the risk and benefit associated with the use of medicine needs to be made on the consumer's behalf, by means of regulations.

\section{Acknowledgements. None.}

Author contributions. LF conceptualised and wrote the article. FO helped to edit and evaluate the manuscript. KdT supervised the work and evaluated the manuscript.

Funding. None.

\section{Conflicts of interest. None.}

1. Ridings JE. The thalidomide disaster, lessons from the past. Methods Mol Biol 2013;947:575-586 https://doi.org/10.1007/978-1-62703-131-8_36

2. Medicines Control Council. http://www.mccza.com/About (accessed 10 April 2017).

3. South Africa. Constitution of the Republic of South Africa Act No. 108 of 1996

4. South Africa. Medicines and Related Substances Act No. 101 of 1965.
5. National Department of Health, South Africa. National Policy for Medicines and Related Substances Act, 1965 (Act No. 101 of 1965). Call up notice for medicines frequently referred to as complementary Act, 1965 (Act No. 101 of 1965). Call up notice for

6. Medicines Control Council. Registration of Medication, 2.01. General information, version 4. 2008. hedtp://www.mccza.com/documents/1d9c57df2.01_General_information_Jul12_v8_showing_changes. http://www.mccza.com/docu,

pdf (accessed 10 April 2017).
MediKredit. NAPPI Allocation Rules Non-Surgical Products. https://www.medikredit.co.za/index. php?option=com_content\&view=article\&id=92\&Itemid=212 (accessed 10 April 2017).

8. Treatment Action Campaign and Another v Rath and Others (12156/05) ZAWCHC 342008 (4) SA $360(\mathrm{C})$

9. South Africa. Medicines and Related Substances Act of 1965. Regulations: Medicines and Related Substances Act. Government Gazette No. 37032, 2013. (Published under Government Notice R870.)

10. South Africa. Allied Health Professions Act No. 63 of 1982. As amended. Section 16(1A)(a).

11. South Africa. Medicines and Related Substances Act of 1965. Regulations: Medicines and Related Substances Act. Government Gazette No. 40158, 2016. Amendment. (Published under Government Notice R858.)

12. Medicines Control Council. Roadmap for registration of complementary medicines. Implementation in accordance with Government Gazette Notice R870 of 15 November 2013. http://www.mccza.com/ documents/66d8cd937.02_Roadmap_for_CAMs_Dec13_v1.pdf (accessed 10 April 2017).

13. National Department of Health, South Africa. Medicines and Related Substances Amendment Act of 1965 (Act No. 14 of 2015). Government Gazette No. 39585:607. 2016

14. National Department of Health, South Africa. Medicines and Related Substances Amendment Act of 1965 (Act No. 72 of 2008). Government Gazette No. 32148:434. 2009.

15. South Africa. Medicines and Related Substances Act of 1965. Regulations: Medicines and Relate Substances Act: Amendment. Government Gazette No. 37032, 2013. (Published under Governmen notice R870.)

6. Medicines Control Council. Complementary Medicines - Discipline-specific safety and efficacy. http:/ www.mccza.com/documents/8b57b09c7.01_CMs_SE_DS_Jun16 v3.pdf (accessed 10 April 2017).

17. Medicines Control Council. Complementary Medicines - Quality, safety and efficacy, http://www. mccza.com/documents/035a3c0c7.01_CAMs_QSE_Dec13_v2_1.pdf (accessed 10 April 2017).

18. Medicines Control Council. Fees payable to the registrar for complementary medicines. http://www. mccza.com/documents/f7bae46017.04_Fees_CAMs_Nov13_vl.pdf (accessed 10 April 2017). 